\title{
Annotations
}

\section{Balloon dilatation in congenital heart disease}

The relief of stenoses in the cardiovascular system without operation has been made possible by the development of balloon catheters that are small enough to enter peripheral vessels yet strong enough not to deform or rupture when inflated to high pressures. The technique was first used for peripheral vascular stenoses and was later adapted for coronary artery stenoses. Dilatation of congenital cardiac lesions became possible with larger balloons after successful relief of congenital valvular and vascular stenoses had been shown experimentally. ${ }^{12}$

In many cases of congenital aortic stenosis, and in most cases of stenosis of the pulmonary valve, the valve is thick but pliable and obstruction results from fusion of the valve cusp. Dilatation probably splits the valve commissures in the same way as surgical valvotomy, although tearing of the leaflets has been reported. ${ }^{3}$ Dilatation of arterial lesions, on the other hand, is achieved by splitting the intima and part of the media, leaving the adventitia intact. ${ }^{12}$ The lesions heal by fibrosis, and in the short term restenosis is uncommon.

\section{Technique}

The technique of balloon dilatation is similar for all lesions. Assessment of the drop in pressure across the stenosis is followed by angiography to identify the site of obstruction and allow the correct size of balloon to be selected. An end hole catheter is positioned across the stenosis and an exchange guide wire passed through it. The catheter is withdrawn and the deflated balloon catheter passed over the guide wire to straddle the stenosis. As the balloon is inflated with dilute contrast medium the correct positioning of the balloon is indicated by 'waisting' at the site of the stenosis. When the pressure rises the waisting disappears as the stenosis is relieved. After dilatation haemodynamic and angiographic assessments are repeated to confirm the success of the procedure.

\section{Indications}

In the fairly short period since it was introduced balloon valvuloplasty has become the safe and effective treatment of choice for stenosis of the pulmonary valve after the neonatal period. ${ }^{+}$The results achieved are similar to those of surgical valvotomy, with a $60-75 \%$ reduction in valve gradient. Balloons $20-30 \%$ larger than the diameter of the valve are safe and produce an appreciably greater reduction in valve gradient than smaller balloons. ${ }^{5}$ Residual obstruction at infundibular level is fairly common but resolves completely within a few months provided that the initial valvuloplasty was successful. ${ }^{56}$ Dysplasia of the pulmonary valve, with thickened, immobile, myxomatous cusps and a small valve annulus, is an uncommon cause of pulmonary stenosis that cannot be cured by valvuloplasty. ${ }^{3}$ Critical pulmonary stenosis in the neonatal period is still best treated surgically because valvuloplasty is technically difficult and the valves are often dysplastic.

Surgical relief of aortic stenosis in childhood and adolescence is safe and acceptably reduces the valve gradient. Aortic regurgitation is common but rarely important. Aortic valvotomy in childhood is, however, usually palliative, and most patients later require either repeat valvotomy or valve replacement. Technically, aortic valvuloplasty is similar to pulmonary valvuloplasty. The balloon catheter is introduced through the femoral artery. The balloon size is usually $1-2 \mathrm{~mm}$ smaller than the aortic valve ring as measured by angiography or echocardiography. The first report of balloon aortic valvuloplasty in 1984 showed that relief of obstruction compared favourably with surgical results and did not produce appreciable valve regurgitation. ${ }^{7}$ If longer follow up confirms these results valvuloplasty may become the first line treatment for children with aortic stenosis. ${ }^{+}$

As surgical relief of critical aortic stenosis in the neonate carries a high mortality we have turned increasingly to valvuloplasty as an alternative. It is, however, difficult to introduce large enough catheters into small femoral arteries. Although coronary balloon catheters have been used successfully in small infants, in our experience they are often too small to produce effective dilatation.

In the Western world congenital mitral stenosis is a rare lesion that is unlikely to respond to balloon dilatation because the valve is usually dysplastic. In developing countries, however, rheumatic mitral valve disease is common in childhood and rheumatic stenosis is caused by fusion of the cusp, which can be dilated by balloon angioplasty. ${ }^{x}$ It requires a trans- 
septal approach to the left atrium and is technically difficult, and its role in the long term management of mitral stenosis in children has not been proved.

Both coarctation and recoarctation can be relieved safely and effectively by angioplasty in children over the age of 12 months. ${ }^{910}$ Angioplasty is not yet a reasonable alternative to surgery in neonatal coarctation because of difficulty of access and because the effect may be transient. Reoperation for recoarctation is not uncommon and has a higher morbidity and mortality, and a lower success rate, than the first operation. Short term results of balloon dilatation already match those of surgery, so that in many centres it is now the treatment of choice. ${ }^{4}$

In coarctation presenting after the age of 12 months balloon dilatation can abolish or reduce the gradient with low morbidity. ${ }^{10}$ The stenosis is relieved by disrupting the vascular wall, and the possibility of late formation of an aneurysm has been raised. ${ }^{11}$ One published abstract reports the formation of aneurysms at short term follow up. Although these patients were asymptomatic, the aneurysms were excised. In our own experience aneurysm formation is rare and associated with inappropriately large balloons. Our first follow up series of patients with native coarctation treated by angioplasty has been so successful that we are continuing to use it for first line treatment after the age of 12 months.

Hypoplasia or stenosis of pulmonary arteries always presents a difficult surgical problem. Balloon angioplasty is feasible, produces relief of stenosis in at least half of these patients, ${ }^{12}$ but is technically difficult and carries a small risk to the patient. Lock et al suggested that balloon dilatation of pulmonary artery stenosis should be considered in children with right heart failure, cyanosis, or supra-systemic right ventricular pressures. ${ }^{4}$ Branch pulmonary artery stenosis is often tolerated badly after a Fontan procedure or repair of tetralogy of Fallot, and even a small drop in pressure across the stenosis may be an indication for treatment. ${ }^{13}$

After either a Mustard or a Senning repair for transposition of the great arteries obstruction of the intra-atrial baffle is fairly rare. Surgical correction is difficult and carries a definite risk. Balloon dilatation is an attractive alternative. ${ }^{14} \mathrm{~A}$ large balloon is used as these lesions are compliant, and, although this technique probably produces its effect by tearing both the intima of the atrial wall and the fibrosis around the baffle, it is safe, technically straightforward, and preferable to further surgery. Relief of stenosis of a Blalock Taussig shunt by balloon dilatation has been reported and may be an alternative to further operation. ${ }^{15}$
We undoubtedly need time to evaluate the results of balloon dilatation of congenital cardiac and vascular lesions. In pulmonary valve stenosis after the neonatal period, however, balloon dilatation is the treatment of choice. In recoarctation of the aorta, in pulmonary artery stenosis, and in baffle obstruction after atrial surgery the risks of operation are high and the success rate only moderate. In these cases balloon dilatation is now the treatment of choice. In our experience angioplasty for coarctation yields encouraging results, although long term follow up is required before we can be certain that it is free of complications. There is a move towards angioplasty for aortic valve stenosis in both children and adults because the results seem to be as good as, and the risks less than, those of surgical valvotomy.

\section{Advantages}

Balloon angioplasty for congenital lesions is considerably cheaper than surgery, requires no more than three days in hospital (compared with 10-14 after most operations), and avoids both a surgical scar and postoperative complications. It is, however, technically difficult in some cases and requires high quality angiography. For this reason it remains the tool of cardiologists. There is perhaps a place for balloon angioplasty in developing countries for managing and treating children with rheumatic heart disease.

\section{References}

' Lock JE, Niemi T, Burke BA, Einzig S, Castaneda-Zuniga WR. Transcutaneous angioplasty of experimental aortic coarctation. Circulation 1982;66:1280-6.

${ }^{2}$ Lock JE, Niemi T, Einzig S, Amplatz K, Burke B, Bass JL. Transvenous angioplasty of experimental branch stenosis in newborn lambs. Circulation 1981:64:886-93.

${ }^{3}$ Kan JS, White RI, Mitchell SE, Farmlett EJ, Donahoo JS, Gardner TJ. Percutaneous transluminal balloon valvuloplasty for pulmonary valve stenosis. Circulation 1984:69:554-60.

${ }^{4}$ Lock JE, Keane JF, Fellows KE. The use of catheter intervention procedure for congenital heart disease. J Am Coll Cardiol 1986;7:1420-3

5 Radtke W, Keane JF, Fellows KE, Lang P, Lock JE. Percutaneous balloon valvotomy of congenital pulmonary stenosis using oversized balloons. J Am Coll Cardiol 1986;8:909-15.

6 Sullivan ID, Robinson PJ, Macartney FJ, et al. Percutancous balloon valvuloplasty for pulmonary valve stenosis in infants and children. Br Heart J 1985:54:435-41.

${ }^{7}$ Lababidi Z, Wu J, Walls JT. Percutaneous balloon aortic valvuloplasty: results in 23 patients. Am J Cardiol 1984;53: 194-7.

${ }^{8}$ Lock JE, Khalilullah M, Shrivastaras, Bahl V, Keane JF. Percutancous catheter commissurotomy in rheumatic mitral stenosis. J Thorac Cardiovasc Surg 1985;87:394-402.

${ }^{9}$ Lock JE, Bass JL, Amplatz K. Fuhrman BP. CastanedaZuniga WR. Balloon dilatation angioplasty of aortic coarctations in infants and children. Circulation 1983;68:109-16.

10 Lababidi ZA. Daskalopoulos DA. Stocckle H Jr. Transluminal 


\section{Hunter and Wren}

balloon coarctation angioplasty: experience with 27 patients. Am J Cardiol 1984;54:1288-91.

1 Locke JE. Now that we can dialte, should we? Am J Cardiol 1984;54:1360.

12 Lock JE, Castaneda-Zuniga WR, Fuhrman BP, Bass JL. Balloon dilatation angioplasty of hypoplastic and stenotic pulmonary arteries. Circulation 1983;67:962-7.

13 di Sessa TG, Yeatman LA, Williams RG, Lois JF, Friedman WF, Laks H. Thrombosis complicating balloon angioplasty of left pulmonary stenosis after Fontan's procedure: successful treatment with intravenous streptokinase. Am J Cardiol 1985;55:610-11.

14 Lou JE, Bass JL, Castaneda-Zuniga W, Fuhrman BP, Rash- kind WJ, Lucas RV. Dilatation angioplasty of congenital or operative narrowings of venous channels. Circulation 1984;70: 457-64.

15 Fischer DR, Park SC, Neches WH, et al. Successful dilatation of a stenotic Blalock-Taussig anastomosis by percutaneous transluminal balloon angioplasty. Am J Cardiol 1984;55:861-2.

STEWART Hunter and Christopher WREN Department of Paediatric Cardiology, Freeman Hospital, Newcastle-upon-Tyne NE7 7DN 